\title{
Emphasis of Naturopathy in the Management of Type 2 Diabetes Mellitus
}

\author{
Authors \\ Rukamani Nair ${ }^{1}$, Deepali Saxena ${ }^{2}$, Naorem Jiteswori Devi ${ }^{3}$, Ranjna Chawla ${ }^{4}$, \\ V. R. Sood ${ }^{5}$ \\ ${ }^{1}$ Medical Superintendent, Bapu Nature Cure Hospital \&Yogashram, Mayur Vihar-I, Delhi-91, India \\ ${ }^{2}$ Senior Research Fellow, Bapu Nature Cure Hospital \&Yogashram, Mayur Vihar-I, Delhi-91, India \\ ${ }^{3}$ Research Officer, Bapu Nature Cure Hospital \&Yogashram, Mayur Vihar-I, Delhi-91, India \\ ${ }^{4}$ Scientist C, GIPMER, New Delhi, India \\ ${ }^{5}$ Physician, Mayur Vihar Phase-2 clinic, Mayur Vihar-II, Delhi-91, India \\ Corresponding Author \\ Dr Rukamani Nair \\ Bapu Nature Cure Hospital \&Yogashram, Mayur Vihar Phase 1, Delhi-91, India \\ Email: drrukamani@bnchy.org,Phone+91-9891775577
}

\begin{abstract}
The aim of the study was to test the efficacy of a four month naturopathy programme for patients with type 2 diabetes mellitus. In this randomized controlled study, 91 patients were selected as subjects, among them 46 participants in the intervention group were asked to attend 60 minutes of naturopathy session for a period of 4 months. The sessions were conducted five times in a week for first month, thrice in a week for second month, twice in a week for third month and once in a week for fourth month. The control group 45 subjects did not receive any naturopathy intervention only medications. Basal recordings of following criterion variables namely, System score (B.P, weight, BMI \& W/H ratio), glycemic status (blood sugar fasting, post prandial and HBA1C), lipid profile (cholesterol, triglycerides and HDL), oxidative stress (glutathione peroxidase and total antioxidative capacity), hormonal status (adiponectin, insulin resistance, insulin sensitivity and beta cell function)were assessed before and after the period of four months in patients with Type 2 Diabetes Mellitus.The study showed a significant improvement inglycemic status (blood glucose fasting and PP, HBAIC), HDL, Adiponectin, glutathione peroxidase, Insulin sensitivity and beta cell function in intervention group while control group showed significant improvement in only few parameters. Naturopathy helps in inducing positive health, alleviating the symptoms of disease by acting at physical and mental levels.

Keywords: Type 2 Diabetes mellitus, Naturopathy, Fasting blood glucose (FBG), Post prandial blood glucose (PPBG), Body Mass Index (BMI).
\end{abstract}

\section{INTRODUCTION}

Type 2 diabetes mellitus is a chronic metabolic lifestyle disorder characterized by an abnormally elevated level of blood sugar and excretion of excess glucose through urine. Its prevalence is growing rapidly throughout the world affecting approximately 285 million people worldwide, that will increase to 439 million by $2030^{\text {( [1], [2] ) }}$. In type 2 diabetes mellitus, insulin is reduced quantitatively. The target cells are hyporesponsive to insulin 
resulting in hyperglycemia as well as glycosuria and if uncontrolled, can lead to multiple complications including ischemic heart disease, stroke, blindness, limb amputations as well as dysfunction of nerves and kidneys ${ }^{[3]}$.

The human and economic toll of type 2 diabetes mellitus is likely to grow globally in the foreseeable future due to increasing rates of urbanization, ruralurban migration, physical inactivity, adoption of sedentary life style and unhealthy diet habits ${ }^{([4],[5])}$. Nature cure believes that all the diseases arise due to accumulation of morbid matter in the body and if scope is given for its removal, it provides cure or relief.

Naturopathy is feasible, safe and compatible with other treatment systems in offsetting chronic diabetic conditions like hyperglycemia, hyperinsulinemia and insulin resistance with reduced population burden of diabetes. It may primarily stress to correct all the factors involved like glucose intolerance, insulin insensitivity, obesity, dyslipidemia, hypertension and stress and then allow the body to recover itself ${ }^{[6]}$.

\section{RESEARCH DESIGN \& METHODS \\ Population \& recruitment}

The study subjects were recruited through advertisements (wall posters, newspaper, banners) and organizing camps in nearby localities of the Hospital. Their age ranged from 35 to 60 years. The study protocol was approved by the Institutional Ethical Committee. Informed consent was obtained from study participants. The study was conducted for 4 months (44 sittings) of periods. All subjects were screened by taking a medical history and clinical examination.

\section{Study Groups}

This randomized study with 91 subjects was conducted at Bapu Nature Cure Hospital \&Yogashram, Delhi, India. Among them 46 participants in the intervention group (Group-1) underwent combined therapy of naturopathy and allopathic medication and 45 subjects in control group (Group-2) were treated only with allopathic medications. All sessions were done under supervision - in the presence of a qualified naturopathy expert.

\section{Naturopathy intervention}

The Naturopathy intervention was provided as a residential treatment for a period of four months at Bapu Nature Cure Hospital \&Yogashram. The sessions were conducted five times in a week for first month, thrice in a week for second month, twice in a week for third month and once in a week for fourth month. Naturopathy session included Mud pack (20 minutes), Massage (20 minutes), and Hip bath (20 minutes).

Mud Therapy: Mud pack was applied to the patients of interventional group for 20 minutes over the abdominal region on empty stomach by the use of clay pack which is free from contamination. It helps to correct the imbalance of the digestive and endocrinal organs, which remain under active in diabetic patients resulting in accumulation of toxins. Mud pack on abdomen absorbs heat and produces soothing and cooling effect. It also improves blood circulation, removes congestion and tones up the tissues and organs ${ }^{[7,8,9]}$.

Massage Therapy: Sesame oil was smeared on the abdomen and spine to the patients of interventional group for 20 minutes which enhances not only blood circulation but also tones up the muscles while improving structural and functional status and hence insulin sensitivity. Massage also generates heat with increased circulation of blood bringing down all the impurities to the channel and expelling through sweat or urine. It is thus highly beneficial in the treatment of diabetes ${ }^{[10]}$.

Cold Hip Bath $\left(22^{\circ} \mathrm{C}\right.$ to $\left.32^{\circ} \mathrm{C}\right)$ : was given to the patients for 20 minutes which produces profound effect upon all bodily functions especially of the abdomen.It excites contraction of the muscular structures of visceral and thus helps to stimulate the 


\section{Outcome Parameters}

Clinical assessments of the patients were performed at the time of enrolment (baseline) and after 4 months of intervention. Clinical examination included measurement of symptoms score (urination, blurred vision, fatigue, and thirst). Other outcome measures included System score (B.P, weight, BMI \& W/H ratio), glycemic status (blood sugar (fasting, post prandial and HBA1C), lipid profile (cholesterol, triglycerides and HDL), oxidative stress (glutathione peroxidase and total antioxidative capacity), hormonal status (adiponectin, insulin resistance, insulin sensitivity and beta cell function).

\section{Results}

All data were statistically analysed using SPSS 16. The standard deviation was calculated. The significant values were expressed in terms of ' $\mathrm{P}$ ' value by applying paired ' $\mathrm{t}$ ' test to compare within the groups.

The socio-demographic information of patients in both the groups is presented in Table-1. Finding shows that majority $(54.34 \%)$ in group 1 and $(46.66 \%)$ in group 2 of the diabetic patients were in the age group of 50-60 years; $54.34 \%$ of them were male in group 1 and $55.55 \%$ in group 2. Most of them received High school/Intermediate education. Regarding their occupation $36.9 \%$ of them were doing household jobs in intervention group. 54.34\% were vegetarians. Most respondents in the intervention group are above poverty line $(84.78 \%)$. With regard to their duration of illness $50 \%$ of them were having diabetes between three and six years.

Significant improvement was observed in glycemic status (blood glucose fasting and PP), HBA1C, HDL, Adiponectin, glutathione peroxidase, Insulin sensitivity and beta cell function, in the intervention group (taking combined therapy of naturopathy and allopathic medicines) after four months treatment as compared to control group (taking only allopathic medicines) which showed significant improvement in only few parameters (Table 2). The results suggested an encouraging role of naturopathy in controlling type II diabetes.
Data on the clinical symptoms of respondents with diabetes in both the groups are shown in Table 3. In group patients better improvement in urination was observed as $(0 \%)$ patients were found in severe category at $4^{\text {th }}$ month as compared to $(39.1 \%)$ at baseline, whereas in group $2,(14.3 \%)$ patients were found in severe category as compared to $(44.4 \%)$ at baseline. On comparing blurred vision improvement was observed in both the groups. In case of fatigue, reduction was observed in both the groups as (10\%) patients were found in severe category at $4^{\text {th }}$ month as compared to $(39.1 \%)$ at baseline in group 1 and $(14.3 \%)$ patients were found in severe category at $4^{\text {th }}$ month as compared to $(44.4 \%)$ in group 2 . Thirst was shown better improvement in intervention group as $(6.7 \%)$ patients were found in severe category at $4^{\text {th }}$ month as compared to $(8.7 \%)$ at baseline whereas no improvement was observed in control group. 
Table 1: Table1: Demographic Scenarios of Diabetic respondents (\%)

\begin{tabular}{|l|c|c|}
\hline CHARACTERISTICS & Group-1 (Intervention) (\%) & Group-2 (Control) (\%) \\
\hline Gender & & 55.55 \\
\hline Male & 54.34 & 44.44 \\
\hline Female & 45.65 & \\
\hline Age in Years & & 11.11 \\
\hline $30-40$ & 19.56 & 42.22 \\
\hline $40-50$ & 26.08 & 46.66 \\
\hline 50-60 & 54.34 & 44.44 \\
\hline Duration of disease & & 22.22 \\
\hline 1-3 years & 23.91 & 6.66 \\
\hline 3-6 years & 50 & 26.66 \\
\hline 6-9 years & 10.86 & 42.22 \\
\hline$>9$ years & 15.21 & 13.33 \\
\hline Occupation & & 35.55 \\
\hline Service & 21.7 & 4.44 \\
\hline Business & 21.7 & 4.44 \\
\hline Household jobs & 36.9 & 15.55 \\
\hline Others & 10.86 & 22.22 \\
\hline None/ Retired & 8.69 & 53.33 \\
\hline Educational Status & & 8.88 \\
\hline Illiterate & 15.21 & 28.88 \\
\hline Primary/Middle & 15.21 & 71.11 \\
\hline High school/intermediate & 41.3 & \\
\hline Graduate and above & 28.26 & \\
\hline Socioeconomic Status & & \\
\hline Below poverty line & 54.78 & \\
\hline Above poverty line & & \\
\hline Marital Status & & \\
\hline Married & & \\
\hline Unmarried/Single & & \\
\hline Type of Food & & \\
\hline Vegetarian & & \\
\hline Non Vegetarian & & \\
\hline & & \\
\hline
\end{tabular}


Table 2: Paired t-test, mean comparison for paired data

\begin{tabular}{|c|c|c|c|c|c|}
\hline \multirow{2}{*}{ Parameters } & \multirow{2}{*}{ Time } & \multicolumn{2}{|l|}{ Intervention } & \multicolumn{2}{|l|}{ Control } \\
\hline & & Mean + SD & $\mathrm{P}$ value & Mean + SD & $\mathrm{P}$ value \\
\hline \multirow[t]{2}{*}{ WEIGHT } & Baseline & $77.34 \pm 14.96$ & & $68.25 \pm 13.74$ & \\
\hline & 4th Month & $76.3 \pm 15.5$ & 0.202 & $68.1 \pm 11.9$ & 0.222 \\
\hline \multirow[t]{2}{*}{ BMI } & Baseline & $30.26 \pm 4.71$ & & $27.13 \pm 5.58$ & \\
\hline & 4th Month & $29.7 \pm 4.6$ & 0.203 & $27.3 \pm 5.0$ & 0.334 \\
\hline \multirow[t]{2}{*}{ W/H RATIO } & Baseline & $0.96 \pm 0.07$ & & $0.97 \pm 0.05$ & \\
\hline & 4th Month & $0.96 \pm 0.06$ & 0.577 & $0.98 \pm 0.06$ & 0.964 \\
\hline \multirow[t]{2}{*}{ B.P (Systolic) } & Baseline & $131.18 \pm 18.00$ & & $125.77 \pm 17.42$ & \\
\hline & 4th Month & $128.7 \pm 12.1$ & 0.173 & $126.4 \pm 15.5$ & 0.232 \\
\hline \multirow[t]{2}{*}{ B.P (Diastolic) } & Baseline & $82.65 \pm 8.17$ & & $79.81 \pm 9.33$ & \\
\hline & 4th Month & $78.3 \pm 17.4$ & 0.141 & $76.1 \pm 15.4$ & 0.328 \\
\hline \multirow{2}{*}{ SUGAR FASTING } & Baseline & $155.73 \pm 64.40$ & & $147.73 \pm 70.14$ & \\
\hline & 4th Month & $137.8 \pm 49.9^{* *}$ & 0.001 & $169.5 \pm 65.0$ & 0.276 \\
\hline \multirow[t]{2}{*}{ SUGAR PP } & Baseline & $252.82 \pm 92.39$ & & $247.66 \pm 74.45$ & \\
\hline & 4th Month & $207.9 \pm 75.4^{* * * *}$ & 0.000 & $262.3 \pm 83.0$ & 0.976 \\
\hline \multirow[t]{2}{*}{ HBA1C } & Baseline & $9.3 \pm 1.7$ & & $9.0 \pm 1.9$ & \\
\hline & 4th Month & $8.0 \pm 1.6^{* * * *}$ & 0.000 & $8.1 \pm 1.6^{* *}$ & 0.002 \\
\hline \multirow{2}{*}{ TOTAL CHOLESTEROL } & Baseline & $178.2 \pm 43.4$ & & $186.4 \pm 10.7$ & \\
\hline & 4th Month & $184.5 \pm 40.7$ & 0.369 & $191.0 \pm 54.5$ & 0.552 \\
\hline \multirow[t]{2}{*}{ TRIGLYCERIDES } & Baseline & $173.0 \pm 103.6$ & & $201.6 \pm 183.8$ & \\
\hline & 4th Month & $161.1 \pm 97.2$ & 0.265 & $173.4 \pm 135.7^{*}$ & 0.019 \\
\hline \multirow[t]{2}{*}{ HDL } & Baseline & $41.8 \pm 11.1$ & & $41.1 \pm 12.0$ & \\
\hline & 4th Month & $56.07 \pm 17.3^{* * *}$ & 0.000 & $50.6 \pm 18.3^{* * *}$ & 0.000 \\
\hline \multirow[t]{2}{*}{ TAC } & Baseline & $1.5 \pm 0.3$ & & $1.5 \pm 0.34$ & \\
\hline & 4th Month & $1.7 \pm 0.4$ & 0.145 & $1.5 \pm 0.21$ & 0.378 \\
\hline \multirow[t]{2}{*}{ GLUTATHIONE PEROXIDASE } & Baseline & $360.4 \pm 30.5$ & & $352.01 \pm 41.8$ & \\
\hline & 4th Month & $345.0 \pm 28.9^{* * *}$ & 0.000 & $355.0 \pm 35.1$ & 0.718 \\
\hline \multirow[t]{2}{*}{ ADIPONECTIN } & Baseline & $7.8 \pm 7.5$ & & $8.24 \pm 6.5$ & \\
\hline & 4th Month & $12.3 \pm 9.3^{*}$ & 0.025 & $9.78 \pm 8.4$ & 0.159 \\
\hline \multirow[t]{2}{*}{ INSULIN SENSITIVITY } & Baseline & $56.5 \pm 27.6$ & & $55.9 \pm 32.2$ & \\
\hline & 4th Month & $92.6 \pm 61.0^{* *}$ & 0.005 & $71.3 \pm 32.6^{*}$ & 0.015 \\
\hline \multirow[t]{2}{*}{ INSULIN RESISTANCE } & Baseline & $5.1 \pm 3.0$ & & $7.0 \pm 4.2$ & \\
\hline & 4th Month & $4.2 \pm 3.2$ & 0.101 & $4.6 \pm 3.5^{* *}$ & 0.007 \\
\hline \multirow[t]{2}{*}{ BETA CELL FUNCTION } & Baseline & $62.0 \pm 53.1$ & & $73.7 \pm 63.4$ & \\
\hline & 4th Month & $127.8 \pm 92.3^{* * *}$ & 0.002 & $73.5 \pm 46.2$ & 0.990 \\
\hline
\end{tabular}

Note: $*(\mathrm{P}<0.05), * *(\mathrm{p}<0.01)$ and $* * *(\mathrm{p}<0.001)$. 
Table 3: Symptoms Score (\%)

\begin{tabular}{llllllll}
\hline \multirow{2}{*}{ Test } & \multirow{2}{*}{ Time } & \multicolumn{2}{l}{ Intervention } & \multicolumn{3}{c}{ Control } \\
\cline { 3 - 8 } & & Normal & Mild & Severe & Normal & Mild & Severe \\
\hline \multirow{2}{*}{ Urination } & Baseline & 61.5 & 3.8 & 34.6 & 44.4 & 16.7 & 38.9 \\
& 4th Month & 69.2 & 28.8 & 1.9 & 48.1 & 38.9 & 13.0 \\
\hline \multirow{2}{*}{ Blurred Vision } & Baseline & 63.5 & 25.0 & 11.5 & 42.6 & 31.5 & 25.9 \\
& 4th Month & 73.1 & 21.2 & 5.8 & 50.0 & 35.2 & 14.8 \\
\hline \multirow{2}{*}{ Fatigue } & Baseline & 28.8 & 32.7 & 38.5 & 31.5 & 29.6 & 38.9 \\
& 4th Month & 53.8 & 40.4 & 5.8 & 31.5 & 55.6 & 13.0 \\
\hline \multirow{2}{*}{ Thirst } & Baseline & 48.1 & 7.7 & 44.2 & 38.9 & 16.7 & 44.4 \\
& 4th Month & 63.5 & 32.7 & 3.8 & 51.9 & 44.4 & 3.7 \\
\hline
\end{tabular}

\section{DISCUSSION}

Complementary and alternative medicine has been increasingly becoming popular among consumers of healthcare ${ }^{[11]}$. The ultimate aim of Naturopathic medicine is to promote the inherent power within the human body and to accelerate self-healing capacity ${ }^{[12]}$.

Normally, blood glucose levels are tightly controlled by insulin, a hormone produced by the pancreas. When the blood glucose elevates, insulin is released from the pancreas to normalize the glucose level. If the pancreas does not produce enough insulin or the produced insulin does not work properly, the glucose cannot enter the body cells. So glucose stays in blood which makes the blood sugar level high. A study of Lima (2008) and Fenicchia (2004) showed that yoga and naturopathy help to reduce blood sugar. ${ }^{[13]}$.

Diabetes control by naturopathy following hydrotherapy enhances the muscle capacities to metabolize the sugar level in blood and increase blood circulation throughout the body. These lower the excessive high sugar levels in blood and take it to normal levels. Hydrotherapy helps to reduce stress, detoxify the body, cure insomnia, reduce excess fats hence doing away with obesity and do away with diabetes mellitus type $2^{[14]}$.

Retrospective observational studies also suggest ND care reduces risk for T2DM and hypertension, including improved glucose control and reduced blood pressure, respectively ${ }^{([15],[16])}$.

Three published results ([17]-[19]) of two trials and one unpublished preliminary study have examined the positive effect of massage on normalizing blood glucose.

Mud therapy gives coolness to the body. It dilutes and absorbs the toxic substances of body and ultimately eliminates them from body ${ }^{[20]}$. A study demonstrates the modifications in risk-factors that occur with long-term naturopathic care for T2DM with notable percentages of patients achieving improvements in glucose levels as measured by HbA1c and blood pressure measures ${ }^{[21]}$ (Bradley et al., 2009)

The finding of the above said studies support the present study.

\section{CONCLUSION}

The current study provides evidence that if practiced regularly, a combined intervention of naturopathy and conventional medications is an effective alternative treatment for type 2 diabetes mellitus. This indicates that naturopathy can be recommended as a strong adjuvant in the treatment of type 2 diabetes mellitus. However we need further to conduct long-term large scale studies in this direction to draw more conclusive results.

\section{ACKNOWLEDGEMENT}

The authors would like to acknowledge Ministryof Ayurveda, Yoga \& Naturopathy, Unani, Siddha and Homeopathy (AYUSH), Government of India for their support. The authors also express appreciation to the participants whose cooperation and dedication made this study possible. 


\section{REFERENCES}

1. R. Sharma, H. Amin, G. Ruknuddin, and P. Prajapati, "Efficacy of Ayurvedic remedies in type 2 diabetes: A review through works done at Gujarat Ayurved University, Jamnagar," J. Med. Nutr. Nutraceuticals, vol. 4, no. 2, p. 63, 2015.

2. J. E. Shaw, R. A. Sicree, and P. Z. Zimmet, "Global estimates of the prevalence of diabetes for 2010 and 2030," Diabetes Research and Clinical Practice, vol. 87, no. 1. pp. 4-14, 2010.

3. Satynarayana U. Biochemistry. 2nd ed. 2002; Books and Allied; 587-603.

4. A. Ramachandran, R. C. Wan Ma, and C. Snehalatha, "Diabetes in Asia," The Lancet, vol. 375, no. 9712. pp. 408-418, 2010.

5. A. Ramachandran, R. Ambady, C. Snehalatha, a Samith Shetty, and a Nanditha, "Primary prevention of Type 2 diabetes in South Asians--challenges and the way forward.," Diabet. Med., vol. 30, no. 1, pp. 26-34, 2013.

6. Underwood, E. J. Trace elements in human and animal nutrition. Acad. Press, New York, London 1971.

7. Sethi AKD. Combating Allergy Naturally. January 20. 2007. 74-80 p.

8. Joshi KS. Speaking of Yoga and NatureCure Therapy. Sterling Publishers; 2013.

9. Important therapeutic modalities used in Naturopathy. 2006th ed. Central council of naturopathy and yoga; 2006. 1,5,47 p.

10. J.H. Kellogg, Art of Massage. University of Michigan Library, 1895

11. Nair PMK, Arankalle DV, Sriloy M, Sathyanath D. Effectiveness of Naturopathic Interventions on reducing the Erythrocyte Sedimentation Rate in Patients with Chronic Inflammatory Disorders. International Journal of innovative research \& development.2015;4: 183-186

12. Nair PM, Nanda A. Naturopathic medicine in India. Focus Altern Complement Ther 2014; 19:140-7
13. G. S. Soni, G. S. Soni, R. Soni, and S. Sharma, "Impact of Naturopathic Treatments and Yogic Practices on Blood Sugar and Blood Pressure in Randomly Selected Voluntaries of Diabetes Mellitus.," 2013.

14. Maria I, Yesuraja AT. The Role of Naturopathy in the Management of Diabetes. Glob J Res Anal. 2014;3(6):205-6.

15. Bradley R. et al. Description of clinical risk factor changes during naturopathic care for type 2 diabetes. J Altern Complement Med. 2009;15(6):633-638.

16. Bradley R, Observed Changes in Risk during Naturopathic Treatment of Hypertension. Evid Based Complement Alternat Med. 2011. p. 826751. Epub 2011 Mar 13.

17. Field T. Massage therapy for infants and children. J Dev Behav Pediatr. 1995;16:10511.

18. Field T, Hernandez RM, LaGreca A, Shaw K, Schlanberg S, Kuhn C. Massage therapy lowers blood glucose levels in children with diabetes mellitus. Diabetes Spectrum. 1997;10:237-9.

19. Vest G. Acupressure, breath awareness help diabetes patients. Massage Magzine. 2000;86:64.

20. R. Rastogi, "Therapeutic uses of Mud therapy in Naturopathy," Indian J. Tradit. Knowl., vol. 11, no. 3, pp. 556-559, 2012.

21. R. Bradley, E. Kozura, H. Buckle, J. Kaltunas, S. Tais, and L. J. Standish, "Description of Clinical Risk Factor Changes During Naturopathic Care for Type 2 Diabetes," J. Altern. Complement. Med., vol. 15, no. 6, pp. 633-8, 2009. 